\title{
Safeguarding Adult Reviews: Informing and Enriching Policy and Practice on Self-Neglect
}

\begin{tabular}{|r|l|}
\hline Journal: & The Journal of Adult Protection \\
\hline Manuscript ID & JAP-02-2020-0003.R1 \\
\hline Manuscript Type: & Research Paper \\
\hline Keywords: & $\begin{array}{l}\text { Safeguarding Adult Reviews, Self-Neglect, Evidence, Research, Multiple } \\
\text { exclusion homelessness, Alcohol misuse }\end{array}$ \\
\hline \multicolumn{2}{|l}{} \\
\hline
\end{tabular}

\section{SCHOLARONE ${ }^{m}$ \\ Manuscripts}


Safeguarding Adult Reviews: Informing and Enriching Policy and Practice on Self-Neglect?

\section{Introduction}

This article has two purposes. The first is to update the database of safeguarding adult reviews (SARs) featuring self-neglect, reported annually since 2015 (Braye et al., 2015a; Preston-Shoot, 2016a; 2017a; 2018; 2019). The database continues to expand. Although data held by NHS Digital ${ }^{1}$ and reviews held by the SCIE repository ${ }^{2}$ do not allow conclusive statements, it is likely that selfneglect cases are more regularly reviewed than most if not all other types of abuse and neglect. In thematic reviews (Braye and Preston-Shoot, 2017; Manson, 2017; Preston-Shoot, 2017b) cases involving self-neglect have been prominent.

The second purpose is to explore the degree to which SARs are research-enriched. Historically, use of research has been variable. Cambridge (2004) found little attempt to link inquiries to broader knowledge or research. He argued that use would add conceptual depth to reports and inform the distillation of positive policy, organisational and practice responses to abuse and neglect. Braye and Preston-Shoot (2017) found that only a minority of SARs drew explicitly on research evidence to support analysis. More positively, perhaps, Preston-Shoot (2017b) found that $57 \%$ of his sample referenced research reports and/or national guidance. However, just under a third drew on other SARs and serious case reviews (SCRs), representing a missed opportunity to learn from similar cases. The quality markers make only passing reference to research when focusing on the rigour of the analysis. Research evidence about what constitutes good practice should be accurate and up-to-date (SCIE and RiPfA, 2018).

\section{Methodology}

As previously, the research focused on four research questions: what is the nature of the self-neglect cases being reviewed? What types of recommendations are being made? What themes emerge as findings from reviewed cases and what are their implications for policy and practice? The main source for locating reviews was through searching SAB websites for published SARs (November 2019). This approach has been used by other researchers (Manthorpe and Martineau, 2015); Martineau et al., 2019). Websites demonstrate marked variability in terms of accessibility and quality. SAB annual reports for 2018/19 were also read where available since they should provide terms of reference and summary findings for commissioned reviews, including those unpublished (DHSC, 2018). Compliance with this statutory guidance requirement varied. One unpublished review was obtained through a personal contact.

The England repository for SARs, available through the Social Care Institute for Excellence website, was accessed. It remains incomplete; not all the SARs referenced in this database are available through the repository. It remains impossible to navigate its contents by type of abuse/neglect.

Although the legislative context differs, included in this database once again are reviews commissioned by Adult Protection Committees in Scotland and SABs in Wales.

\footnotetext{
${ }^{1} \mathrm{NHS}$ Digital publishes annually the number of SARs undertaken, breaking the number down regionally. However, it does not collect data on the types of abuse and neglect within the cases being reviewed. ${ }^{2}$ The SCIE repository is incomplete.
} 
Safeguarding Adult Reviews: Informing and Enriching Policy and Practice on Self-Neglect?

The same analytic approach is used here as previously (Braye et al., 2015a; 2015b), adapted from studies of SCRs in children's services (Brandon et al., 2011). Firstly, the key characteristics of each case and each review are recorded, followed by the frequency and content of recommendations. Secondly, themes are extracted from a cross-case analysis, organised around four domains. Termed descriptive research (Manthorpe et al., 2015), these four domains of analysis - direct practice with the individual, the professional team around the adult, the organisations around the professional team, and SAB governance - have enabled an evidence-based model to be built (Preston-Shoot, 2019), a set of practice standards that has been explicitly used in some of the reviews in this sample.

Case numbering continues the database sequence (Preston-Shoot, 2019). Not all reviews explicitly reference self-neglect. However, cases that contained reference to one or more of the constituent elements (living in squalor, hoarding, significant neglect of health and wellbeing, rejection of care and support) (DHSC, 2018) have been included.

\section{Case Characteristics}

In the complete sample $(n=246)$ some cases involve the presence of more than one person. That said, where gender is specified, men outnumber women (147/106). The largest age group is now people aged $60-75$ (25\%), followed by people aged over 76 (23\%) and those aged 40-59 (22\%). Those aged 21-39 comprise just 4\% of the sample where age is known. Other researchers have also noted the predominance of cases involving older and especially older old people (for example, Bestjan, 2012). Ethnicity is not routinely recorded.

Within this sub-sample and across the sample as a whole, refusal of services ( $n=26$ and 127 ) and lack of self-care ( $n=39$ and 148 ) remain prominent, and often combined in cases. There were fewer cases in this sample involving lack of care of one's environment ( $n=4$ and 58). All three components of selfneglect are present in 15 cases within this sub-sample and 72 cases overall. Prominent too within the reviewed cases are scenarios involving alcohol and/or drug abuse and/or episodes of homelessness. Finally, almost all the adults had died ${ }^{3}$, a trend noted by other researchers (Bestjan, 2012; Manthorpe and Martineau, 2011). NHS Digital statistics ${ }^{4}$ also show that, for $2018 / 2019$ for example, a majority of reviews concerned adults who had died. Perhaps SABs should review SAR referral pathways.

One review was commissioned by a City Council rather than a SAB (242) and concerned a homeless person. Indeed, SABs have clearly engaged in reviewing the deaths of homeless people. Twelve other reviews ${ }^{5}$ also concern individuals who were either homeless when they died or had experienced homelessness.

\begin{tabular}{|l|l|l|l|}
\hline \multicolumn{4}{|l|}{ Table One: Case Characteristics } \\
\hline Case & SAB, date, case & Gender, age & Living situation \\
\hline
\end{tabular}

\footnotetext{
${ }^{3}$ Case 226 and the wife in case 234 are the exceptions.

${ }^{4}$ https/:digital.nhs.uk/data-and-information

${ }^{5}$ Cases 203, 206, 207, 208, 212, 216, 225, 238, 239, 240, 245, 246.
} 
Safeguarding Adult Reviews: Informing and Enriching Policy and Practice on Self-Neglect?

\begin{tabular}{|c|c|c|c|}
\hline 196 & $\begin{array}{l}\text { Leicestershire and Rutland, } \\
\text { 2017/18, NS }\end{array}$ & Female, 54 & Not known \\
\hline 197 & Scottish APC, 2018, Mrs A & Female, 70 & Lived with husband \\
\hline 198 & Barnsley, 2018, Mrs T & Female, 86 & Lived alone \\
\hline 199 & Barnsley, 2018, RG & Male 68 & Lived alone \\
\hline 200 & Barnsley, 2018, Jack & Male, 68 & Lived alone \\
\hline 201 & Devon, 2018, Adrian Munday & Male, 51 & $\begin{array}{l}\text { Lived alone but accommodation } \\
\text { cuckooed }\end{array}$ \\
\hline 202 & Walsall, 2016/17, no name & Female, not given & Homeless \\
\hline 203 & $\begin{array}{l}\text { Newham, Islington, City of } \\
\text { London \& Hackney and } \\
\text { Lambeth, 2018, Mr Yi }\end{array}$ & Male, not given & Homeless \\
\hline 204 & Haringey, 2019, Ms Taylor & Female, 71 & Lived alone \\
\hline 205 & Bromley, 2019, Ms A & Female, 28 & Lived with grandmother \\
\hline 206 & Milton Keynes, 2019, Adult B & Male, 33 & Homeless \\
\hline 207 & Wiltshire, 2018, Adult D & Male, 40 & Homeless \\
\hline 208 & $\begin{array}{l}\text { North Tyneside \& } \\
\text { Northumberland, no date, } \\
\text { Leanne Patterson }\end{array}$ & Female, 36 & Multi-occupancy hostel \\
\hline 209 & Lancashire, 2019, Adult G & Male, 51 & Lived alone \\
\hline 210 & Wiltshire, 2019, Adult C & Male, not given & Lived alone \\
\hline 211 & $\begin{array}{l}\text { West Berkshire, 2018, } \\
\text { Aubrey }\end{array}$ & Male, 45 & Lived alone \\
\hline 212 & Bexley, 2018, Ms AB & Female, 45 & Lived alone \\
\hline 213 & Rochdale, 2019, Adult 2 & Female, not given & Unclear \\
\hline 214 & Slough, 2018, Mrs M & Female, 91 & Lived with son \\
\hline 215 & $\begin{array}{l}\text { Buckinghamshire, 2019, } \\
\text { Adult V }\end{array}$ & Male, early 70s & Lived alone \\
\hline 216 & Essex, 2018, Frank & Male, 55 & $\begin{array}{l}\text { Homeless, living temporarily in a } \\
\text { hotel }\end{array}$ \\
\hline 217 & Hertfordshire, 2017, Stanley & Male, 60s & Lived alone \\
\hline 218 & $\begin{array}{l}\text { Salford SAB and Community } \\
\text { Safety Partnership, no date, } \\
\text { Mary }\end{array}$ & Female, 85 & Lived alone \\
\hline 219 & $\begin{array}{l}\text { Lincolnshire, 2017, thematic } \\
\text { review }\end{array}$ & & Multiple cases of financial abuse \\
\hline 220 & Lancashire, 2019, May & Female, 70 & Lived alone \\
\hline 221 & $\begin{array}{l}\text { Greenwich, 2019, Mrs A and } \\
\text { Miss B }\end{array}$ & Female, not given & $\begin{array}{l}\text { Mother living alone and daughter } \\
\text { visiting regularly }\end{array}$ \\
\hline 222 & West Berkshire, 2018, Paul & Male, not given & Lived with cousin \\
\hline 223 & Lambeth, 2019, Mr E & Male, 62 & Lived alone \\
\hline 224 & Lambeth, 2019, Martin & Male, 51 & Lived alone \\
\hline 225 & $\begin{array}{l}\text { Kingston-upon-Thames, } \\
\text { 2018, SU }\end{array}$ & Male, 61 & Lived with partner \\
\hline
\end{tabular}


Safeguarding Adult Reviews: Informing and Enriching Policy and Practice on Self-Neglect?

\begin{tabular}{|c|c|c|c|}
\hline 226 & $\begin{array}{l}\text { Cheshire West and Chester, } \\
\text { 2019, David }\end{array}$ & Male, 78 & Care home resident \\
\hline 227 & Enfield, 2019, Mr A & Male, 70 & Lived alone \\
\hline 228 & $\begin{array}{l}\text { Newham, 2019, thematic } \\
\text { review }\end{array}$ & $\begin{array}{l}4 \text { mean aged } \\
\text { between } 75 \text { and } 97\end{array}$ & 3 lived alone; one lived with son \\
\hline 229 & Barnet, no date, $\mathrm{YY}$ & Male, not given & Nursing home \\
\hline 230 & Warrington, no date, Robert & Male, 74 & Lived with partner \\
\hline 231 & Wolverhampton, 2019, Edith & Female, 80 & Lived with nephew \\
\hline 232 & $\begin{array}{l}\text { West Sussex, 2019, Mrs } \\
\text { Patricia Pelham }\end{array}$ & Female, 70 & Lived with husband \\
\hline 233 & Waltham Forest, 2018, Mark & Male, 48 & Lived alone \\
\hline 234 & Leeds, 2020, Mr Mrs A & $\begin{array}{l}\text { Male, 50; Female, } \\
45\end{array}$ & Couple living together \\
\hline 235 & Leeds, 2020, Mr B & Male, 64 & Lived alone \\
\hline 236 & Sutton, 2019, EE & Male, 61 & Supported living accommodation \\
\hline 237 & $\begin{array}{l}\text { Cornwall, 2019, thematic } \\
\text { review with one new case }\end{array}$ & Female, 87 & Lived with family \\
\hline 238 & $\begin{array}{l}\text { Tower Hamlets, 2020, Ms H } \\
\text { and Ms I thematic review }\end{array}$ & $\begin{array}{l}\text { Female, 52; } \\
\text { Female, } 33\end{array}$ & $\begin{array}{l}\text { Living in flat temporarily; } \\
\text { homeless }\end{array}$ \\
\hline 239 & $\begin{array}{l}\text { Oldham, 2020, thematic } \\
\text { review }\end{array}$ & $\begin{array}{l}3 \text { men, aged } 43,62 \text {, } \\
76 ; 1 \text { woman, } 34\end{array}$ & One homeless, three living alone \\
\hline 240 & $\begin{array}{l}\text { Manchester, 2020, thematic } \\
\text { review }\end{array}$ & $\begin{array}{l}\text { Seven men aged } \\
\text { between } 28 \text { and } 60\end{array}$ & Homeless \\
\hline 241 & $\begin{array}{l}\text { Tower Hamlets, } 2020, \mathrm{Mr} F \\
\text { and } \mathrm{Mr} \text { G themed review }\end{array}$ & $\begin{array}{l}\text { Two men, aged } 73 \\
\text { and } 68\end{array}$ & Both men lived alone \\
\hline 242 & $\begin{array}{l}\text { Worcester City Council, } \\
2018, C\end{array}$ & Male, 74 & Homeless \\
\hline 243 & Gwent, 2018, Caroline & Female, 64 & Lived alone \\
\hline 244 & Havering, 2018, GR & Male, 91 & Lived alone \\
\hline 245 & $\begin{array}{l}\text { Bournemouth \& Poole and } \\
\text { Poole Community Safety } \\
\text { Partnership, 2016, Harry }\end{array}$ & Male, 22 & Lived independently \\
\hline 246 & Solihull, 2019, Rachel & Female, 20 & $\begin{array}{l}\text { Lived in supported } \\
\text { accommodation }\end{array}$ \\
\hline
\end{tabular}

\section{SAR Characteristics}

Within this sub-sample, self-neglect is predominantly the central focus ${ }^{6}$. Across the whole sample ( $n=246)$, where information is available, it is the central focus in $65 \%$ of cases, implicit in $18 \%$ and peripheral in $13 \%$. Where detail is given, the dominant methodology adopted a systemic orientation that used a combination of learning events and/or interviews alongside independent management

\footnotetext{
${ }^{6}$ Self-neglect was judged implicit in 4 cases $(207,242,245,246)$ and peripheral in $8(201,203,206,209,219$, $225,226,232)$.
} 
Safeguarding Adult Reviews: Informing and Enriching Policy and Practice on Self-Neglect?

reviews, combined chronologies and panel deliberation ${ }^{7}$. Eight reviews used a learning lessons approach. Seven adopted a thematic approach ${ }^{8}$. Thematic reviews enable SABs to adopt a proportionate approach where SAR referrals focus on the same type of abuse/neglect. They also facilitate a deeper dive into systemic issues across a number of cases of self-neglect and/or social isolation and financial abuse. Another interesting development is joint commissioning, with SARs being combined with DHRs or mental health homicide investigations ${ }^{9}$.

Most reviews in this sub-sample have been published either in full or as executive summaries ${ }^{10}$.

\section{Recommendations}

Within this sub-sample ( $n=51), 30$ reviews contained ten or fewer findings/recommendations. Numbers, however, can be misleading since individual recommendations sometimes comprised several elements. Within this sub-sample, recommendations are most commonly directed to a Safeguarding Adult Board (37/51), in 18 cases just to the SAB that then has the responsibility to determine what action to require from partner agencies. Frequently allocated specific recommendations are Adult Social Care (22), NHS Trusts (16), Police (5) and Clinical Commissioning Groups (CCGs) (7). There are occasional recommendations for GPs, care providers and third sector organisations, Children's Social Care, the Fire and Rescue Service, Ambulance Trusts, the National Probation Service and Housing. Ten reviews make recommendations to all the SAB's partner agencies. Across the entire sample $(n=246), 70 \%$ of SARs make recommendations to a SAB and $37 \%$ to Adult Social Care. NHS Trusts receive recommendations in $26 \%$ of cases, Clinical Commissioning Groups in $17 \%$, Housing in $11 \%$, GPs in $9 \%$ and the Police in 10\%; safeguarding is everyone's business.

Some reviews reference recommendations offered by agencies as part of IMRs and/or reflective interviews. Ten cases in the sub-sample do not allocate named responsibility for implementing specific recommendations, $33 \%$ of cases across the entire sample, undermining the quality marker of transparency.

\section{Themes within recommendations}

Four broad categories of recommendations are retained - staff support, review process, best practice and procedures (Braye et al., 2015a), the contents of which mirror what other researchers have also found (for example, Manthorpe and Martineau, 2011).

\section{Staff support}

Within the sub-sample ( $n=51), 36$ reviews recommend training and 17 improvements to supervision, support and managerial oversight. Across the full sample, $60 \%$ of reviews contain recommendations

\footnotetext{
728 SARs adopted this approach. Two reviews employed the Welsh model (Kingston et al., 2018). Appreciative inquiry (Sharp et al., 2016), multi-agency partnership review, significant incident learning process (Clawson and Kitson, 2013) and learning together (Fish et al., 2008) were each used once.

${ }^{8}$ Cases 219, 228, 237, 238, 239, 240, 241.

${ }^{9}$ Cases 218, 221, 245.

${ }^{10}$ Cases 196, 197 and 202 do not appear to have been published. Cases 196 and 202 are mentioned in a SAB annual report. Case 237 is referred to in conference and SAB presentations.
} 
Safeguarding Adult Reviews: Informing and Enriching Policy and Practice on Self-Neglect?

regarding training and $31 \%$ supervision, including access to specialist advice. Investing in training will prove ineffective without also focusing on workplace development to ensure that staff can embed in practice acquired knowledge and skills (Braye et al, 2013). Perhaps implicitly acknowledging this observation, 11 reviews make recommendations relating to staff workloads and resources available to practitioners.

\section{Review process}

This sub-sample continues the trend of small numbers of recommendations regarding how the review process was managed; 3 contain recommendations, for instance about the impact of Coroner inquests on timely completion of reviews and, significantly in the context of central government concern ${ }^{11}$, about approaches to reviewing deaths of homeless people. Of greater concern remains the importance of learning from reviews, possibly cognisant of Wood's (2016) criticisms of the lack of impact of Serious Case Reviews (SCRs). Nineteen make recommendations about dissemination locally and nationally, whilst 23 contain recommendations regarding subsequent quality assurance, auditing outcomes of learning and SAR impact on service development and practice. Nine offer recommendations concerned with following through action plans. Again, on the theme of reviews making a difference, five highlight the SAB's leadership role on developing strategic approaches to concerns about sexual exploitation, fire risk, mate crime and transient homeless people. Two recommend changes to SAB membership or structure. Across the whole sample, $13 \%$ contain recommendations concerning future management of the review process and $31 \%$ about using the report for learning and service development.

\section{Best practice}

Within the best practice theme in this sub-sample, mental capacity assessments drew 10 recommendations, including the importance of exploring people's choices, executive capacity and unravelling the notion of lifestyle choice. Five contain recommendations about person-centred, relationship-based approaches, and 15 about different ways of seeking to engage with people who are refusing services. Nine SARs contain recommendations concerning knowledge and use of the law, and 15 on assessment and involvement of family carers. Noticeable in this sub-sample are 6 SARs that contain recommendations regarding transitions, especially hospital discharge, 5 that focus on appropriateness of, and standards within placements, and 8 that focus on planning, monitoring and reviewing care packages. Five SARs refer explicitly to advocacy provision and seven to community awareness-raising about self-neglect.

Across the entire sample, best practice in mental capacity assessments continue to dominate; $34 \%$ of reviews contain recommendations here. Mindful of the challenges of working with adults who self-neglect, $26 \%$ of reviews contain recommendations concerning engagement and $22 \%$ remind practitioners and managers of the importance of relationship-centred practice. The relationship focus extends to family members; $22 \%$ of reviews highlight assessment of carers, thinking family and understanding family dynamics. $17 \%$ of SARs contain recommendations about legal literacy.

\section{Procedures}

${ }^{11}$ https://www.gov.uk/government/publications/the-rough-sleeping-strategy 
Safeguarding Adult Reviews: Informing and Enriching Policy and Practice on Self-Neglect?

Recommendations continue to place faith in procedures. Within the sub-sample, 39 SARs recommend the development and/or review of guidance. 28 focus on referral and assessment and 20 on case management, including the use of section 42 enquiries, safeguarding or self-neglect pathways, and reviews. Recommendations regarding working together occur in 27 cases, information-sharing in 23. Eighteen cases refer to the importance of recording. Five cases recommend that legal advice is available and/or obtained and three focus on the process of managing service design. Noticeable in this sub-sample, partly because of the focus on homelessness, are 18 SARs with recommendations regarding commissioning of services.

Across the whole sample ( $n=246$ ), $69 \%$ of SARs recommend the development and/or review of guidance for staff; $52 \%$ focus on referral and assessment pathways. $57 \%$ make recommendations regarding inter-agency working, whilst $52 \%$ focus also on case management. Recommendations regarding recording occur in $35 \%$ of cases, information-sharing in $40 \%$.

\section{Cross-case analysis}

This sample has a strong emphasis on homelessness, especially concerning people who experience multiple exclusion homelessness ${ }^{12}$. This comprises extreme marginalisation that includes childhood trauma, physical and mental ill-health, substance misuse and experiences of institutional care (Mason et al., 2017/18) and often results in self-neglect. Across the four domains, their findings represent a microcosm of familiar systemic issues, namely:

- In practice with the person, the need to assess likelihood and significance of risks, executive capacity and the impact of trauma; to consider advocacy; to challenge assumptions of lifestyle choice; to demonstrate creativity and persistence in attempting to engage.

- Working as a team around the person, the need to improve safeguarding and legal literacy, including scrutinising decisions about intentional homelessness; to strengthen integrated whole system working, including active use of high risk panels and key workers.

- Organisations around the team should provide support for staff as the work can be exceptionally challenging; commissioners and providers should review gaps in services, such as the availability of accommodation for people with co-morbidities.

- On governance, SABs should work with Health and Wellbeing Boards, Community Safety Partnerships and Local Children's Safeguarding Partnerships to ensure governance oversight of how services respond to multiple exclusion homelessness.

Four SARs ${ }^{13}$ organise their findings around the self-neglect evidence-base of best practice, developed from research (Braye et al., 2011; 2014) and reviews (Preston-Shoot, 2019). That evidence-base is used explicitly here to reflect on the findings from the SARs in this sample.

Domain A: practice with the individual adult in their social situation

Making Safeguarding Personal

\footnotetext{
${ }^{12}$ Cases 196, 202, 206, 212, 216, 238, 239, 240, 242, 245, 246

${ }^{13}$ Cases 235, 238, 239, 240.
} 
Safeguarding Adult Reviews: Informing and Enriching Policy and Practice on Self-Neglect?

A person-centred approach comprises proactive rather than reactive engagement, and a detailed exploration of the person's wishes, feelings, views, experiences, needs and desired outcomes. Maintenance of contact and continuity is advised so that trust can be established. Concerned curiosity is helpful, characterised by gentle persistence, skilled questioning, conveyed empathy and relationship-building skills. Building up a picture of the person's history may help to uncover what is driving and maintaining self-neglect and hoarding.

Within the sample there are references to good practice, for instance using different approaches to engage individuals (210), taking time to establish trust and relationships $(213,215,223,230,232)$, and persevering in the face of rejection $(243,244)$. Nonetheless, there are criticisms of the lack of curiosity about an individual's life journey $(214,220,224,228,243)$, and of the failure to explore what lies behind behaviour, including hoarding and non-engagement $(210,211,214,215,217,220,222,223$, $228,230,242)$. There are reminders to follow-up the failure to keep appointments $(209,215)$ and to not rely just on telephone calls when attempting to establish contact. In one case information about provider concerns was not shared with the service user (211).

\section{Autonomy}

Exploring what may appear a lifestyle choice should be attempted to understand what might lie behind a person's refusal to engage. Loss, trauma, shame and fear often lie behind refusals to engage. There is considerable criticism of assumptions about lifestyle choice, often revolving around attitudes or pre-judgement regarding misuse of alcohol, with consequent failure to explore the meaning behind patterns of behaviour $(200,207,210,212,213,215,223,224,228,231,233,238,239,243)$. As reviews observe, this can result in under-estimation of the impact of trauma and self-neglect $(216,233)$ and missed opportunities to prevent deterioration and to refer for mental health input (216).

\section{$\underline{\text { Assessment }}$}

Assessment requires time to address the impact of adverse experiences, including issues of loss and trauma. It also should explore repetitive patterns. Comprehensive risk assessments are required, especially in situations of service refusal. Thorough mental capacity assessments are also advised, which include understanding and consideration of executive capacity, recognising that a person's articulate skills and good cognition test results might mask difficulties.

Good practice is noted with respect to mental capacity (217) and care and support assessments (209, 220). However, in relation to capacity, risk and/or care and support assessments, criticism falls into distinct categories, namely:

- Missed opportunities to assess, for example of co-morbidities, service refusal and/or noncompliance with treatment $(209,210,211,212,214,215,216,222,223,228,233,244)$;

- Incomplete assessments, for example of evidence of coercive control, loss and/or risk (213, 220, 221, 224, 231);

- Lack of thoroughness or robustness $(208,209,210,229,236,243)$, for example of fluctuating capacity when risks are high $(205,228)$, including underestimation of risk $(209,218)$, responding to individual episodes rather than seeing and addressing patterns (228) and not according mental and physical health parity of esteem $(210,216,242)$; 
Safeguarding Adult Reviews: Informing and Enriching Policy and Practice on Self-Neglect?

- Assumption of capacity $(200,218,224,244)$ and failure to explore executive capacity through functional assessments, as advised in guidance (NICE, 2018) $(209,224)$;

- Delayed assessments and/or reviews, a lack of timeliness (209, 215, 216);

- Services not working together but conducting assessments in isolation $(200,239,240)$.

\section{Planning}

Care plans should be thorough and reviewed regularly. Transition, for example hospital discharge and placement commissioning, requires particular attention. Good, person-centred planning, is found (205), for instance regarding hospital discharge (220) and arrangements for mental health treatment (210). Conversely, planning for hospital discharge is found to be rushed, with inadequate functional assessments and/or multi-disciplinary involvement, with necessary arrangements not in place (209, $211,212,215,228,231,235)$. The adequacy of discharge summaries is also criticised, with information about care arrangements and/or safeguarding concerns not fully itemised $(231,243)$. NICE guidance $(2015 ; 2016)$ does not seem to be embedded in practice. Elsewhere standards of planning are assessed as poor (213), with the suitability of different options not considered (242), and with inadequate arrangements to meet need or manage risks $(208,209,216)$.

\section{$\underline{\text { Family and social context }}$}

Family and friends may have significant contributions to offer to assessments and care planning, both to support the person to engage and to inform understanding of their circumstances. SARs in this sample provide timely reminders. Records do not consistently note details of next of kin $(209,239$, 240). Family members are not involved in care planning or in supporting their relatives when appointments are missed $(210,211,220)$. When family members are acting as a circle of support, carer assessments are overlooked $(226,227,228)$. The role of the nearest relative in mental health legislation may not be understood (210). The main critique, however, is the absence of professional curiosity about family and relationship dynamics, including evidence of coercive and controlling behaviour, and the failure to explore and challenge what is being said, especially when information provided appears contradictory $(198,200,214,218,222,230,231,244)$. Lack of legal literacy about when it is lawful (Data Protection Act 2018) to share and request information about individuals at risk of abuse and neglect (including self-neglect) may be one reason for the findings here.

A person's social context should also be explored, their community networks (204, 210, 216, 235). Although not explicitly referenced in any SAR in this sample, attention to social networks and community presence draws attention to the need to embed contextual safeguarding (Firmin, 2017) in adult safeguarding.

Advocacy should be commissioned where this might assist a person to engage with assessments, service provision and treatment. Case 212 comments positively on use of advocacy. However, in other cases advocacy does not appear to have been considered $(217,231)$. Appropriate arrangements should also be made for interpreter services (207).

\section{Domain B: the professional team around the adult}

\section{Counteracting silo working}


Safeguarding Adult Reviews: Informing and Enriching Policy and Practice on Self-Neglect?

Particularly important in complex and challenging cases, inter-agency communication and collaboration is facilitated where this is coordinated by a lead agency and key worker. Occasionally SARs comment on good practice, working together to establish contact with a person and/or to respond to needs and risks, such as pressure ulcer care $(209,216,231)$. However, criticism of silo working and of agencies not pulling together emerges frequently $(205,208,210,214,216,217,222$, $233,240,243,244)$. SARs highlight the lack of communication between services $(217,223,224,243)$, for example at key points of transition for a person (201), reflective of a lack of ownership and accountability (222).

One indicator of working together is referral practice. Some SARs in this sample identify good practice in sending and responding to referrals $(209,210,211,218)$. Others, however, observe that practitioners seemed unclear about referral pathways $(214,239)$ or that referrals were incomplete or unclear, for example about whether a care and support assessment (section 9 Care Act 2014) was being requested or a section 42 enquiry $(200,224,226,229,232)$. Responses were not always timely (214) and thresholds could act as a barrier (233).

\section{Whole system meetings}

Multi-agency meetings should be convened to pool information and assessments of risk and mental capacity, agree a risk management plan, and consider legal options. Outcomes of plans should be reviewed routinely. Occasionally SARs comment positively on the use of multi-agency meetings (216). More often, however, there are familiar criticisms. Meetings are considered but not convened, with differences of opinion between professionals remaining unresolved (211), or there does not appear to have been any consideration of taking cases to panels or holding conferences $(205,207,210,214$, $217,222,229,231,233,239,240)$. Consequently, relevant information is not shared and there remains no agreement about how needs will be met or risks managed. Whilst multi-agency meetings and panel discussions can be used to support practice in complex cases, share responsibility, facilitate information-sharing and plan risk management, some reviews highlight uncertainty about which panels to use or how to escalate concerns $(212,231,233)$.

\section{Information-Sharing}

Information-sharing should be comprehensive so that all agencies involved possess the full picture. Referrals should be detailed where one agency is requesting the assistance of another in order to meet a person's needs. Good practice is reported occasionally $(210,230)$. More often, reviews criticise the poor quality of information-sharing across services $(205,211,215,216,218,220,221,227,228,242$ ) with the result that no single agency has a complete picture (200). Specific examples include hospital discharge letters giving incomplete information about a person's needs and vulnerabilities $(217,243)$, GPs not being aware of when Police send safeguarding or welfare concerns to the local authority (218) or not responding to information that they receive (224), and services not sharing safeguarding concerns with family members (220). One case (209) criticises the Police for limited informationsharing when taking a person to an emergency department.

\section{Knowledge and use of safeguarding and legal pathways}

Policies and procedures for working with adults who self-neglect, adopted by the $S A B$, should be evident in how staff approach each case. The duty to enquire (section 42, Care Act 2014) should be used where this would assist in coordinating the multi-agency effort. Some reviews in this sample 
Safeguarding Adult Reviews: Informing and Enriching Policy and Practice on Self-Neglect?

identify good practice when raising or escalating safeguarding concerns $(205,211,214,215,220,230)$. Others, however, identify situations where safeguarding procedures should have been followed (214, $215,243)$ or referrals taken forward into strategy discussions or enquiries $(216,222,231,233)$. Use of safeguarding pathways is missing in self-neglect cases $(207,210,216,220,227)$, opportunities are missed (229).

Practitioners and managers, for example in multi-agency meetings, should seek out and have access to specialist legal (199), mental capacity and mental health advice. It should be clear how the relevance of diverse legal options to assist with case management, sometimes referred to as legal literacy, was evaluated. Reviews frequently draw attention to lack of understanding of relevant legal rules and the need to consider all options, including Court of Protection and the High Court's inherent jurisdiction $(210,217,231)$.

\section{$\underline{\text { Recording }}$}

Clear and thorough records should be maintained of assessments, reviews and decision-making. Sometimes reviews advise on standards, namely that recording should be factual and clear, with judgements supported by evidence (230). More often, they observe that records are either incomplete, inaccurate or out-of-date $(200,209,216,218,231)$. It may be difficult therefore to understand why a referral was made, or how self-neglect developed $(209,220)$. It may be difficult to track whether multi-agency discussions took place about risk (244). Also in focus is the use by agencies of different IT systems, with the result that key information may not be accessible when needed across services $(205,231)$.

\section{Domain C: organisations around the professional team}

\section{Commissioning provision}

Managers should demonstrate and record case oversight, including decision-making about commissioning and the outcome of contract monitoring of service providers. Reviews in this sample criticise the lack of management oversight, for example of case reviews, hospital discharges and ongoing concerns $(204,209,220,227,244)$. Commissioning has a much stronger presence in this sample. Several reviews focus on commissioning for services to meet the needs of people experiencing multiple exclusion homelessness $(238,239,240,242)$ or point to gaps in services $(212,217,220)$, for example with respect to dual diagnosis, supported accommodation and psychological support. Other reviews comment on the management of provider concerns $(211,217)$ and the identification and response to organisational abuse (226). There is also a focus on the need to improve monitoring commissioned packages of care $(222,243)$.

\section{Working environment}

Supervision promotes reflection and critical analysis of the approach being taken to the case. Regular supervision is essential $(210,217,222,227,230)$, for example to explore the approach taken to a case.

Support should be available for staff working with people who are hard to engage, resistant and sometimes hostile. In one case (200) support was seen as crucial since there were complex legal, ethical and practice issues to be resolved. Specialist legal, mental capacity and safeguarding advice is 
Safeguarding Adult Reviews: Informing and Enriching Policy and Practice on Self-Neglect?

available and any guidance given should be recorded. There is little reference to such advice in this sample of reviews.

Workforce and workplace issues are addressed, such as staffing levels, organisational cultures, training and thresholds. The need for training $(207,227)$ and volume of cases $(232)$ emerge occasionally. Case allocation should be based on an appreciation of staff knowledge, skill-sets, capability and capacity. This is not explored in this sample of reviews.

\section{Procedural guidance}

Practice guidance should be available and clearly embedded in case and supervision notes. Reviews in this sample point to the absence of frameworks to guide practice for work with adults who self-neglect and/or misuse substances $(207,223,224,230,239)$. Occasionally, reviews also refer to procedural guidance being available but not used (213).

\section{Domain D: SABs and inter-agency governance}

\section{Managing reviews}

The SAB will require clear guidance on the process of commissioning and managing the review process in order to meet its statutory duties with respect to SARs (section 44, Care Act 2014). Not all reviews proceeded smoothly, as evidenced in delays in agencies providing information and poor attendance at learning events (215). Delay could also arise due to the complexities of reviewing several cases and the volume of material to consider (221). Adopting a pragmatic or proportionate response sometimes meant that reliance was placed on written documentation, not triangulated with staff interviews, resulting in some lines of enquiry not being fully explored (222).

\section{Effecting change}

The standard here is that SABs disseminate and audit the impact of policies, procedures and reviews regarding self-neglect. Learning from SARs for practice and the management of practice with adults who self-neglect should be routinely disseminated through such mechanisms as 7 minute briefings and workshops. Occasionally SARs refer back to other reviews completed by the SAB in order to explore what has (not) been learned $(222,238)$. Occasionally too reviews comment on the need to develop a framework for practice derived from the findings (230).

\section{A learning mosaic - beyond SARs}

Self-neglect has also featured in Domestic Homicide Reviews (DHRs), commissioned by Community Safety Partnerships, in Independent Investigations (previously known as Mental Health Homicide Reviews), commissioned by NHS England, and in Serious Case Reviews (SCRs) commissioned by Local Safeguarding Children Boards. Learning is also available from case law and judgements from the Local Government and Social Care Ombudsman (LGSCO). The available learning reinforces components of the model of good practice developed through SARs, identified in italics.

DHRs (McAteer, 2013; Hughes, 2014; Hunter, 2015) recommend inclusion of the potential for selfneglect alongside harm to others in risk assessments. They reach familiar conclusions about thinking 
Safeguarding Adult Reviews: Informing and Enriching Policy and Practice on Self-Neglect?

family - the importance of consistently involving family members in risk assessments, of supporting carers and of exploring family dynamics. Concerned curiosity is essential as close relatives may find it difficult to report their fears. They highlight that consistent and persistent refusal to engage or to acknowledge concerns should be treated as a risk factor.

DHRs contain other familiar themes. They emphasise the importance of treating patients in line with guidance for the enhanced care programme approach, highlighting again the importance of legal literacy. They highlight the importance of updated care plans and intervention that addresses repeating patterns. They debate the balance to be struck between Article 8 and Article 2 ECHR rights when considering whether and when significant risks might justify breaching confidentiality to seek information from family members without consent, rather than just listen to their concerns, highlighting again the challenge of balancing autonomy with a duty of care. Kennedy (2018), in a case where significant risks derived from self-neglect, substance misuse, non-engagement and domestic violence, recommended that staff be trained in using a multi-agency risk management meeting approach, including appointment of a lead agency and key worker. The importance of IT systems facilitating information-sharing was also emphasised.

Familiar themes also emerge from SCRs where self-neglect features (Few, 2014; Bournemouth and Poole, 2015). They include:

- Carer's assessments neither offered or completed;

- A culture of professional curiosity is required, for example when taking a history as family members may not easily disclose the full nature of relationship difficulties, which may lead to an under-estimation of risks and vulnerabilities;

- Assessment should include the impact of one person's mental ill-health and self-neglect on others in the family and also what behavioural patterns might suggest about family dynamics; assessment must give appropriate weight to domestic violence;

- Insufficient supervision and management oversight of a complex case;

- Agencies must share information if professionals are to be clearly sighted on all the issues;

- Agencies must follow standards of good practice within the care programme approach;

- Missed opportunities for input from family relatives;

- A think family approach;

- Workloads and lack of expertise in risk assessment affected responses by children's social care and the police.

Two SCRs involve young people under the age of eighteen who self-neglect (Dorset Safeguarding Children Board, 2014; Preston-Shoot, 2016b), demonstrating that this phenomenon is not just one affecting adults. The SCRs highlight the importance of communication between children's social care, adolescent mental health services and adult social care services. They recommend that agencies should:

- Have a protocol for engagement with hard to reach families and young people;

- Consider the impact of case closure decisions on other agencies;

- Assess family dynamics and risks; 
Safeguarding Adult Reviews: Informing and Enriching Policy and Practice on Self-Neglect?

- Assess causes and meaning of behaviour, see events not in isolation but as patterns and use chronologies;

- Support worker resilience;

- Reinforce legal literacy regarding parental responsibility, mental capacity and mental health.

Independent investigation reports add to the disparate strands of the evidence-base. The reviews (Marsden, 2012; Rooney, 2017) highlight the importance of assessment of needs and risks in the complex interaction between mental and physical health, and drug and alcohol abuse, alongside information-sharing and comprehensive discharge planning. Resource shortfalls in staffing and expertise contribute to poor assessments, failure to implement an enhanced care programme approach, and difficulty in responding to non-engagement and high level care and support needs.

The use of legal literacy is illustrated by two recent cases where the local authority applied to the High Court seeking orders through the use of its inherent jurisdiction. In one case the judge determined that the individual lacked mental capacity to understand the risks he was living in, namely extremely neglected accommodation and self-neglect. Orders in his best interest were made under the Mental Capacity Act 2005 (London Borough of Croydon v CD [2019] EWHC 2943 (Fam)). The second case (Southend on Sea v Myers [2019] EWHC 399 (Fam)) involved self-neglect and neglect. The High Court employed its inherent jurisdiction to safeguard an older person who had what was described as a relationship of co-dependency with his adult son.

LGSCO decisions recognise the complexity of self-neglect cases, especially when having to balance autonomy and protection (LGSCO and Buckinghamshire County Council, 2017), but emphasise the importance of taking action when services are refused in situations of obvious deterioration (LGSCO and Windsor and Maidenhead Council, 2019). They remind local authorities of the importance of clear and adequate recording of decisions-making, of commissioners monitoring the care that has been commissioned, of timely assessments and reviews of care and support needs, of avoiding delay in service provision to meet assessed needs, and of thorough mental capacity assessments when an individual's behaviour presents significant risks (LGSCO and Blackburn with Darwen Council, 2017; LGSCO and Buckinghamshire County Council, 2017; LGSCO and Dorset County Council, 2019; LGSCO and Windsor and Maidenhead Council, 2019).

\section{Research Informed and Enriched?}

Turning to the article's second purpose, how many SARs draw explicitly upon research and policy or practice guidance? How many draw on other SARs, including those completed previously by the commissioning SAB? $57 \%$ in this sample of SARs $(n=51)$ referenced research studies and/or nationally available guidance. This percentage hides considerable variability. Some SARs make extensive use of research and guidance (for example 239,240) whilst others may contain only a single reference (226). A word of caution is also necessary. Published executive summaries are often brief and it is possible that the full, unpublished SAR might have drawn on research/guidance and, indeed, other reviews. Nonetheless, greater use of research and/or national guidance would strengthen analysis and learning by enabling comparison with the organisational and practice environment being reviewed (Preston-Shoot, 2017b). 
Safeguarding Adult Reviews: Informing and Enriching Policy and Practice on Self-Neglect?

Only $22 \%$ of the sample made connections with other SARs that had been completed locally or elsewhere. In $31 \%$ of the sample no connection was made with other SARs or SCRs that the SAB had previously completed on self-neglect. This represents a significant missed opportunity to review the impact of learning lessons, namely what has (not changed) locally in terms of policy, organisational and multi-agency collaboration and practice.

It is not unusual to observe that little use is made of research about effective interventions in practice (Serbati et al., 2019) but why does this matter? Firstly, commissioning SARs and using evidence to inform their findings and recommendations is an acknowledgement and expression of accountability. SABs are accountable to several constituencies from which their mandate is drawn and accountable for the development, monitoring and review of adult safeguarding arrangements. Accountability is both explanatory and responsive (Preston-Shoot, 2020). Secondly, responding effectively to the complexities and challenges inherent in adult safeguarding requires that services and practice are based on a robust foundation of best evidence (Marsh and Fisher, 2005). That foundation draws on diverse sources of knowledge, including research alongside practice wisdom, to raise awareness, challenge attitudes and assumptions, and develop policy and practice in ways that respond to complexity, uncertainty, need and risk by assembling a coherent picture of the circumstances surrounding each case (Walter et al., 2004; Lorenz, 2016).

There are, at least, three barriers to confront. One concerns relationships between researchers and practitioners. Building bridges between different communities has been promoted through the development of researcher-practitioner partnerships in generating and discussing findings (for example, Mason et al., 2017/18; Serbati et al., 2019). A second concerns the inaccessibility of research, published behind paywalls. Researchers, historically, have arguably paid insufficient attention to dissemination and mobilisation of their findings through, for example, learning and service development events and briefings that draw out implications for policy and practice (Walter et al., 2004). Equally, however, it takes persistence to seek out research and SAR evidence (Mullen, 2016).

A third barrier is that research is not seen as relevant. This may be because research illustrates what needs to be done but not how it should be done (Marsh and Fisher, 2005), a challenge that may also be voiced about SARs. Doubt may be expressed about whether what has been found effective somewhere else transfers to the local context (Mullen, 2016). Alternatively, the implications of research findings may be edited down because they challenge current beliefs, assumptions and approaches to particular issues, or filtered through what is politically acceptable and financially possible either nationally or locally (Weiss, 1993). Nonetheless, a framework for positive practice can be devised from research and SARs, offering guidance for policy, multi-agency collaboration and practice, on which SABs and their partner agencies can build through training, supervision, commissioning and quality assurance. The model for best practice in responding to self-neglect (Preston-Shoot, 2019a) provides one example of this process.

For SABs and SARs, one conclusion from the foregoing is that the quality markers (SCIE and RiPfA, 2018) could be much more explicit about the value of drawing on research and review findings. 
Safeguarding Adult Reviews: Informing and Enriching Policy and Practice on Self-Neglect?

Another is that reviewers should be encouraged to draw more actively on research and review findings to inform their analysis.

\section{Concluding discussion}

Since the research was completed for this SAR sample, other reviews have been published ${ }^{14}$. These will be included in future analyses alongside reviews that have been commissioned but not yet concluded. Once again, as reported above, not all these reviews use learning from research and published SARs. So, what is to be made of this continuing stream of reviews on self-neglect?

The breadth of the concept of self-neglect, incorporating hoarding alongside behaviour that jeopardises health, may partly explain this picture. However, there are clearly systemic issues locally that individual SARs implicitly expose if not explicitly challenge. These include barriers to implementing the evidence-base for effective practice in self-neglect cases, such as embedding the use of case conferences and multi-agency strategy meetings, and building capability within the workforce.

The themes within the recommendations, and the findings across the domains, betray the layered complexity of transforming adult safeguarding. For example, the quality of practice with individuals in their social situation is inextricably linked to the organisational culture and multi-agency relationships within which it is located, not least supervision, workloads, staff support, strategic and operational collaboration across boundaries, and access to specialist advice. The ability of commissioners to construct an integrated architecture of provision, designed to address the needs of the whole person, is influenced by relationships across health, housing and social care, and political geography locally and nationally. The effectiveness of procedures will depend on whether they are co-produced and perceived to enhance practice or experienced as contributing to practice overload (Northway et al., 2007).

In these respects the onus falls on SABs to seek reassurance that the evidence-base is guiding practice and the management of practice.

Equally there are systemic issues nationally that SARs alone will be incapable of resolving. These include gaps in the law, for example when working with individuals in the long-term grip of substance misuse, and challenges created by current law, for example how legislation perceives of mental capacity or permits information-sharing. The impact of financial austerity on public services, reflected in workloads, thresholds for eligibility and resources to meet needs, will feature here. So too will the coverage in health, medical and social work education of the constituent components of the evidence-base for working effectively with self-neglect specifically, and adult safeguarding generally, such as legal literacy and the developing understanding of executive capacity. The next iteration of the statutory guidance (DHSC, 2018) could helpfully be informed by experiences of the impact of parallel processes on timely completion of reviews. It could also consider whether a strong mandate towards publication of reviews would assist SABs, individually and collectively, to conduct sustained, continuing conversations, drawing on SARs for policy and practice change.

\footnotetext{
${ }^{14}$ For example, by Teeswide SAB (2019) Josh; Camden SAB (2019) Ms UU.
} 
Safeguarding Adult Reviews: Informing and Enriching Policy and Practice on Self-Neglect?

Here the onus falls on SABs, individually and collectively, to use the authoritative knowledge gleaned from SARs to advocate for legislative and policy change, and on central government to learn the lessons.

\section{References}

Bestjan, S. (2012) London Joint Improvement Partnership (JIP): Learning from Serious Case Reviews on a Pan London Basis. London: London Joint Improvement Partnership.

Bournemouth and Poole LSCB (2015) Serious Case Review: Baby N.

Brandon, M., Sidebotham, P., Bailey, S. and Belderson, P. (2011) A Study of Recommendations Arising from Serious Case Reviews 2009-2010. London: Department for Education.

Braye, S. and Preston-Shoot, M. (2017) Learning from Safeguarding Adult Reviews: A Report for the London Safeguarding Adults Board. London: London Safeguarding Adults Board.

Braye, S., Orr, D. and Preston-Shoot, M. (2011) Self-Neglect and Adult Safeguarding: Findings from Research. London: SCIE.

Braye, S., Orr, D. and Preston-Shoot, M. (2014) Self-Neglect Policy and Practice: Building an Evidence Base for Adult Social Care. London: SCIE.

Braye, S., Orr, D. and Preston-Shoot, M. (2015a) 'Learning lessons about self-neglect? An analysis of serious case reviews.' Journal of Adult Protection, 17 (1), 3-18.

Braye, S., Orr, D. and Preston-Shoot, M. (2015b) 'Serious case review findings on the challenges of self-neglect: indicators for good practice.' Journal of Adult Protection, 17 (2), 75-87.

Cambridge, P. (2004) 'Abuse inquiries as learning tools for social care organisations.' In N. Stanley and J, Manthorpe (eds) The Age of Inquiry: Learning and Blaming in Health and Social Care. London: Routledge. Pages 231-254.

Clawson, R. and Kitson, D. (2013) 'Significant Incident Learning Process (SILP) - the experience of facilitating and evaluating the process in adult safeguarding.' Journal of Adult Protection, 15 (5), $237-$ 245.

Department of Health and Social Care (DHSC) (2018) Care and Support Statutory Guidance: Issued under the Care Act 2014. London: The Stationery Office.

Dorset Safeguarding Children Board (2014) Serious Case Review: Family S11.

Few, C. (2014) Serious Case Review in respect of Child D: Overview Report. Derbyshire Safeguarding Children Board. 
Safeguarding Adult Reviews: Informing and Enriching Policy and Practice on Self-Neglect?

Firmin, C. (2017) Contextual Safeguarding: An Overview of the Operational, Strategic and Conceptual Framework. Luton: University of Bedfordshire.

Fish, S., Munro, E. and Bairstow, S. (2008) Learning Together to Safeguard Children: Developing a Multi-Agency Systems Approach for Case Reviews. London: SCIE.

Hughes, G. (2014) Overview Report into the Death of Adult 1. Gwynedd Community Safety Partnership. Domestic Homicide Review Executive Summary.

Hunter, D. (2015) Overview Report. Rochdale Safer Communities Partnership. DHR.

Kennedy, I. (2018) Domestic Homicide Review: Maggie Johnson. Bristol Community Safety Partnership.

Kingston, P., Eost-Telling, C. and Taylor, L. (2018) Comparing Safeguarding Review Methodologies. Preston: Lancashire Safeguarding Boards.

LGSCO and Blackburn with Darwen Council, 2017, Case Number 15020170.

LGSCO and Buckinghamshire County Council, 2017, Case Number 16011871.

LGSCO and Dorset County Council, 2019, Case Number 18000204.

LGSCO and Windsor and Maidenhead Council, 2019, Case Number 17019298.

Lorenz, W. (2016) 'Reaching the person-social work research as a professional responsibility.' European Journal of Social Work, 19 (3-4), 455-467.

Manson, S. (2017) Report from a Thematic Review of Safeguarding Adult reviews within the East Midlands. Nottingham: East Midlands ADASS.

Manthorpe, J. and Martineau, S. (2011) 'Serious case reviews in adult safeguarding in England: an analysis of a sample of reports.' British Journal of Social Work, 41 (2), 224-241.

Manthorpe, J and Martineau, S. (2015) 'What can and cannot be learned from serious case reviews of the care and treatment of adults with learning disabilities in England? Messages for social workers.' British Journal of Social Work, 45 (1), 331-348.

Manthorpe, J., Martineau, S., Ridley, J., Cornes, M., Rosengard, A. and Hunter, S. (2015) 'Embarking on self-directed support in Scotland: a focused scoping review of the literature.' European Journal of Social Work, 18 (1), 36-50.

Marsden, E. (2012) Independent Review into the Care and Treatment of F and G. A Report for NHS South of England (formerly NHS South East Coast). London: Verita. 
Safeguarding Adult Reviews: Informing and Enriching Policy and Practice on Self-Neglect?

Marsh, P. and Fisher, M. (2005) Developing the Evidence Base for Social Work and Social Care Practice. London: SCIE.

Martineau, S., Cornes, M., Manthorpe, J., Ornelas, B. and Fuller, J. (2019) Safeguarding, Homelessness and Rough Sleeping: An Analysis of Safeguarding Adult Reviews. London: Kings College London.

Mason, K., Cornes, M., Dobson, R., Meakin, A., Ornelas, B. and Whiteford, M. (2017/18) 'Multiple exclusion homelessness and adult social care in England: exploring the challenges through a researcher-practitioner partnership.' Research, Policy and Planning, 33 (1), 3-14.

McAteer, K. (2013) Domestic Homicide Review in respect of the death of a Woman. Birmingham Community Safety Partnership. DHR2011/12-03.

Mullen, E. (2016) 'Reconsidering the "idea" of evidence in evidence-based policy and practice.' European Journal of Social Work, 19 (3-4), 310-335.

NICE (2015) Transition between Inpatient Hospital Settings and Community or Care Home Settings for Adults with Social Care Needs. London: National Institute for Health and Clinical Excellence.

NICE (2016) Transition between Inpatient Mental Health Settings and Community or Care Home Settings. London: National Institute for Health and Clinical Excellence.

NICE (2018) Decision-Making and Mental Capacity. London: National Institute for Health and Clinical Excellence.

Northway, R., Davies, R., Mansell, I. and Jenkins, R. (2007) 'Policies don't protect people, it's how they are implemented: policy and practice in protecting people with learning disabilities from abuse.' Social Policy and Administration, 41 (1), 86-104.

Preston-Shoot, M. (2016a) 'Towards explanations for the findings of serious case reviews: understanding what happens in self-neglect work.' Journal of Adult Protection, 18 (3), 131-148.

Preston-Shoot, M. (2016b) Serious Case Review into the Circumstances concerning Kevin. South Tyneside Safeguarding Children Board.

Preston-Shoot, M. (2017a) 'On Self-Neglect and Safeguarding Adult Reviews: Diminishing Returns or Adding Value?' Journal of Adult Protection, 19 (2), 53-66.

Preston-Shoot, M. (2017b) What Difference Does Legislation Make? Adult safeguarding through the Lens of Serious Case Reviews and Safeguarding Adult Reviews. A Report for South West Region Safeguarding Adults Boards. Bristol: South West ADASS.

Preston-Shoot, M. (2018) 'Learning from Safeguarding Adult Reviews on Self-Neglect: Addressing the Challenge of Change.' Journal of Adult Protection, 20 (2), 78-92. 
Safeguarding Adult Reviews: Informing and Enriching Policy and Practice on Self-Neglect?

Preston-Shoot, M. (2019) 'Self-neglect and safeguarding adult reviews: towards a model of understanding facilitators and barriers to best practice.' Journal of Adult Protection, 21 (4), 219-234.

Preston-Shoot, M. (2020) 'Making any difference? Conceptualising the impact of safeguarding adults boards.' Journal of Adult Protection, 22 (1), 21-34.

Rooney, C. (2017) An Independent Investigation into the Care and Treatment of a Mental Health Service User (Miss B) in Rotherham. Manchester: Niche Health and Social Care Consulting.

Serbati, S., Moe, A., Halton, C. and Harold, G. (2019) 'Pathways for practitioners' participation in creating the practice-research encounter.' European Journal of Social Work, 22 (5), 791-804.

Sharp, C., Dewar, B. and Barrie, K. (2016) Framing New Futures through Appreciative Inquiry. Glasgow: IRISS.

Social Care Institute for Excellence and Research in Practice for Adults (2018) Safeguarding Adult Review Quality Markers Checklist. London: SCIE.

Walter, I., Nutley, S., Percy-Smith, J., McNeish, D. and Frost, S. (2004) Improving the Use of Research in Social Care Practice. London: SCIE.

Weiss, C. (1993) 'Where politics and evaluation research meet.' Evaluation Practice, 14 91), 93-106. 